\title{
PRÁTICA PEDAGÓGICA LÚDICA DE PROFESSORES QUE ENSINAM MATEMÁTICA NOS ANOS INICIAIS DO ENSINO FUNDAMENTAL
}

\author{
LUDIC PEDAGOGICAL PRACTICE OF TEACHERS WHO TEACH \\ MATHEMATICS IN THE EARLY YEARS OF FUNDAMENTAL EDUCATION
}

Adelmo Carvalho da Silva ${ }^{1}$

ORCID iD: $\underline{0000-0001-9995-0310}$

Cristina Maria D’Ávila

ORCID iD: $\underline{0000-0001-5946-9178}$

\begin{abstract}
RESUMO
O texto consiste em um recorte da pesquisa de pós-doutorado dos autores, realizada na UFBA/FACED no período de março de 2018 a março de 2019. O estudo teve como objetivo geral analisar a compreensão, organização e desenvolvimento da Prática Pedagógica Lúdica de professores que ensinam matemática aos alunos dos anos iniciais do Ensino Fundamental. Apresentou a seguinte questão: como as professoras de matemática do Ensino Fundamental compreendem, interpretam e organizam suas práticas pedagógicas lúdicas? Foram utilizadas as abordagens da pesquisa qualitativa, do estudo de caso e do método interpretativo para analisar as informações produzidas por quatro professoras de uma escola pública de $1^{\circ}$ e $2^{\circ}$ ciclos. Os instrumentos utilizados para a produção e coleta de dados foram a observação, a entrevista e a análise de documentos. Conclui-se que os professores compreendem o conceito investigado e esforçam-se para desenvolvê-lo nas aulas de matemática.
\end{abstract}

Palavras-chave: Prática pedagógica. Lúdico. Ensino-aprendizagem da Matemática.

\begin{abstract}
The text consists of an excerpt from the authors' postdoctoral research, carried out at UFBA/FACED from March 2018 to March 2019, entitled: Playful pedagogical practices of teachers who teach mathematics in the early years of elementary school. It had as general objective: to analyze the comprehension, organization and development of the Pedagogical Playful Practice of teachers who teach mathematics in the initial years of Elementary School. He posed the following question: how do elementary school math teachers understand, interpret and organize their playful pedagogical practices? The qualitative research, case study and interpretative method approaches were used to analyze the information produced by four teachers from a public school in the 1st and 2nd cycles. The instruments used for the production and collection of data were observation, interview and analysis of documents. It is concluded that teachers understand the concept investigated and strive to develop it in mathematics classes.
\end{abstract}

Keywords: Pedagogical practice. Play. Teaching-learning of Mathematics.

\footnotetext{
${ }^{1}$ Doutor em Educação pela UFPB/JP. Professor da Universidade Federal de Mato Grosso - UFMT, Cuiabá-MT, Brasil. Rua Projetada A, 85. Jardim Petrópolis, Cuiabá, Brasil. CEP: 78070-015. E-mail: adelmoufmt@gmail.com.

2 Doutora em Educação pela UFBA/FACED. Professora da Universidade Federal da Bahia - UFBA, SalvadorBA. Rua Guadalajara, 398 - Barra, Salvador-BA. CEP: 40.140-461. E-mail: cristdavila@ gmail.com.
} 


\section{INTRODUÇÃO}

Pesquisas em educação matemática e documentos oficiais sobre a educação brasileira asseveram que as finalidades do ensino da matemática envolvem dimensões de caráter prático, formativo, cultural e da cidadania. Nesta concepção, a dimensão de caráter prático deve expressar-se não somente na aquisição de conhecimentos essenciais para a resolução de problemas do dia a dia, mas também no desenvolvimento de capacidades fundamentais exigidas pela sociedade. O ensino formativo da matemática deve refletir-se nos aspectos cognitivos, sociais e afetivos, promovendo a independência, a autoconfiança e o prazer de se realizar atividades matemáticas. Assim, ao se conceber a Matemática como um patrimônio cultural e ligada ao progresso da humanidade, deve-se considerar que é importante e fundamental que os alunos compreendam estes aspectos significativos da disciplina. No tocante à cidadania, devese entender que a sociedade está cada vez mais matematizada. Dessa forma, o ensino da disciplina deve contribuir para que os alunos se tornem cidadãos independentes, críticos e confiantes quanto ao uso da matemática nas mais variadas situações cotidianas.

Desta forma, o desenvolvimento da Prática Pedagógica (PP) e da Prática Pedagógica Lúdica (PPL), a última por assumir alguns princípios da PP, deve ajudar as crianças no desenvolvimento de meios que deem sentido à disciplina de matemática e na sua utilização, de forma flexível, nas situações reais da vida.

Do exposto, emergiu o problema da pesquisa: como as professoras de matemática dos anos iniciais do Ensino Fundamental compreendem e organizam suas práticas pedagógicas lúdicas? Para o artigo proposto, apresenta-se o seguinte objetivo geral: Analisar a compreensão e desenvolvimento da Prática Pedagógica Lúdica de professores que ensinam matemática no primeiro e no segundo ciclo do Ensino Fundamental.

\section{LUDICIDADE E ENSINO DA MATEMÁTICA NA ESCOLA}

A perspectiva do "ensino lúdico", reduzida ao simplismo pedagógico, ainda é compreendida por muitos professores como uma mera atividade prático-pedagógica, utilitarismo pedagógico, aulas divertidas, brincadeiras e jogos. Tais atividades, que até podem ser lúdicas, não garantem o estado de ludicidade ao qual se refere Luckesi (2014, p. 19): "ludicidade tem a ver com experiência interna pessoal, e, ao mesmo tempo e consequentemente, com experiência interna coletiva" - que se assume nesta pesquisa. Nesta direção, a investigação proposta não nega a cultura adquirida na coletividade, assume, em concordância com Luckesi 
(2018, p. 140), que "ludicidade pertence ao mundo interior de cada pessoa e esse tem uma história, tem uma biografia, que é determinante no que se refere às sensações, percepções e aos julgamentos". Em consonância com o debate, Lopes (2014, p. 29) afirma que a ludicidade "é um fenômeno de natureza consequencial à espécie humana. É uma condição de ser humano que se manifesta e produz uma diversidade de efeitos".

Desta forma, ao se utilizar de atividades lúdicas no contexto educacional, pode-se afirmar que seu alcance contribui de forma significativa no processo de ensinar e aprender matemática na escola, posto que a matemática é uma construção humana. Aprendê-la deveria ser um desejo natural e prazeroso para as pessoas - as quais, por sua vez, possuem uma biografia que determina, sobremaneira, o ato de apreender matemática na escola. Ludicidade não transcursa apenas do mundo exterior, mas da relação do sujeito entre mundo exterior $\mathrm{x}$ interior x exterior. Destaca-se, então, que o sujeito lúdico faz parte de uma cultura; assim sendo, segundo Lopes (2014, p. 26-27),

enquanto fenômeno da condição do ser do Humano, está presente em cada pessoa e em qualquer cultura. Manifesta-se diversamente e os seus efeitos são potencializadores de intercompreensão [...] a condição humana da ludicidade não está subjugada a calendários ou imposições institucionais, uma vez que pode manifestarse em qualquer contexto situacional.

Ainda sobre o conceito de lúdico, Huizinga (2000, p. 30) esclarece que "desde muito cedo, o ludus latino foi suplantado por um derivado de jocus grego, cujo sentido específico (gracejar, troçar) foi ampliado para o de jogo em geral." A definição filosófica do autor remetese à ideia de que o jogo não é um meio e, sim, um fim. Assim, o jogo de caráter lúdico é livre de objetivos secundários; em outras palavras, as intencionalidades pedagógicas na escola passam despercebidas pelo aluno praticante. Seu objetivo está em promover, simplesmente, satisfação por realizá-lo, sem perceber outras finalidades para aquela prática, mesmo que existam. Sobre o jogo, Bemvenuti (2013, p. 21) afirma que

(...) tem origem na palavra ludus, que designa, além de escola, o divertimento e o jogo de palavra. Já o adjetivo ludius, do verbo ludere, designa exercício e treinamento. Importante aqui compreender que para os romanos, havia um espaço lúdico no espetáculo de cada jogo, isto é, existia a compreensão da diferença entre o combate real e a encenação. O jogo é a encenação, é a mimesis do real, é o exercício imaginário vivido no jogo.

Nessa perspectiva, Kishimoto (2011, p. 15), ao teorizar sobre o termo, alerta que: 
adultos, crianças, (...) e uma infinidade de outros. Tais jogos, embora recebessem a mesma denominação, têm suas especificidades.

A variedade de fenômenos que podem ser considerados jogos mostra a complexidade da tarefa de defini-lo. Contudo, ressalta-se sua importância para a compreensão das condutas lúdicas, as reflexões prévias acerca do jogo durante o processo histórico, pois o caráter polissêmico atribuído ao jogo, como também ao lúdico, promoveu, desde a antiguidade, interpretações e utilidades diversas a esses fenômenos.

Dessa forma, tratar do lúdico pela ótica histórico-filosófica tem por objetivo compreender o conceito e seus usos ao longo da história. Verifica-se, com base nos apontamentos de Huizinga (2000), que este fenômeno existe para além da cultura, não dependendo dela para se constituir. Isto implica na aceitação de que o lúdico está intimamente ligado à cultura, em grande parte à subjetividade de cada pessoa. É nesse sentido que a pesquisa realizada e o texto apresentado norteiam.

Neste aspecto, deve-se refletir sobre como o lúdico é compreendido na relação entre professor e aluno no âmbito escolar. Assim, é necessário delimitar dois paradoxos relativos às práticas lúdicas no contexto educacional: o de seriedade/obrigação e o de prazer e atividade livre. O primeiro corresponde ao ponto em que a seriedade atribuída por um agente externo à atividade lúdica chega às vias de transformá-la em um exercício de extrema responsabilidade e de obrigatoriedade, o que pode descaracterizá-la da condição de lúdica, visto que a liberdade da atividade, caso seja cerceada pelo professor, tem como objetivo apenas a participação do educando, desconsiderando se a sensação, para ele, é lúdica ou não. Destaca-se que é a prática, devido à falta de compreensão dos professores sobre o conceito e finalidade do lúdico, que mais se realiza pelos professores no contexto da sala de aula.

O segundo surge por meio do imaginário social da escola de que o prazer é garantido ao realizar atividades ditas lúdicas. Outro equívoco absurdo da escola. No contexto escolar, os jogos e as brincadeiras não podem ser entendidos como atividades lúdicas apenas por apresentarem natureza de jogo e brincadeira. Para serem lúdicas, as atividades precisam fazer com que as crianças se entreguem a elas, e a entrega deve despertar prazer nelas.

O prazer é consequência, ocorre naturalmente pela liberdade, escolha e entrega dos sujeitos à atividade oferecida. Quando se determina que a atividade deva ser prazerosa, e por isso lúdica, desconsidera-se que o prazer possa ou não surgir, o que, de certa forma, obriga os participantes a iniciarem as atividades rotuladas como prazerosas. Portanto, o prazer é individual, interno, subjetivo. Ademais, manifesta-se de forma muito particular em cada pessoa, aluno e, no caso de atividades lúdicas, até naqueles que observam os envolvidos na brincadeira. 
O "alcance" do prazer na atividade deriva da liberdade atribuída pelo sujeito que participa da atividade. Deste modo, quando a atividade proposta é alicerçada em liberdade, o prazer pode ser encontrado pelos participantes como consequência do sentir-se livre. A liberdade imprime aos participantes a escolha de participar, fazer, quebrar as regras, fazer diferente, reconstruir.

Dantas (2017, p. 111) reflete sobre essa tênue linha que pode caracterizar ou descaracterizar uma atividade educativa de caráter lúdico pela via do prazer. O que chama atenção quando se pede a profissionais dos anos iniciais do Ensino Fundamental sinônimos para ele - o lúdico - é a tendência a oferecer "prazeroso" e nunca "livre". Assim, "ludicamente" é visto como prazerosamente, alegremente, e não "livremente". Dantas (2017) expõe que a natureza do compromisso que a atividade assume, devido à forma como ela é apresentada para os alunos, pode transitar do lúdico ao trabalho. Na concepção de Dantas (2017, p. 114), o trabalho é "entendido como qualquer ação instrumental subordinada a um fim externo e a um produto, corresponde, portanto, àquela para onde tende a atividade lúdica”. O lúdico, assim, apresenta-se como preparação para algo que virá, como um treinamento imaginário que proporciona ao aluno constituir condições para conviver em sociedade; no caso específico, no mundo do trabalho, essas atividades preconizadas como lúdicas podem afastar-se do campo lúdico, da cultura lúdica, na medida em que a obrigação de sua realização seja apresentada aos discentes.

Para Brougère (2017), a cultura lúdica ${ }^{3}$, como toda cultura, é um produto da interação social, isso significa que essa experiência não é apenas transferida para a criança, mas ressignificada por ela. É com base nas relações estabelecidas entre criança, ambiente lúdico e meio social que se constrói uma cultura lúdica. Conforme o autor, a cultura lúdica resulta de uma experiência lúdica, produzida pelo sujeito social baseada nessas relações e interações com indivíduos, ações e objetos materiais. Ao brincar, o aluno poderá vivenciar momentos lúdicos. Essas experiências, no decorrer do tempo, compõem um grande acervo de sensações e estímulos, que colaboram para alimentar uma cultura lúdica já existente. A cultura lúdica influencia as relações do indivíduo com o meio e com os outros, mas não é determinante; os alunos, por serem sujeitos culturais, ressignificam e reconstroem o ambiente lúdico, atribuem sentidos às atividades e, assim, colaboram para o desenvolvimento do seu conhecimento social. $\mathrm{Na}$ educação escolar, caso haja intencionalidade educativa, esse processo de "troca" de experiências das crianças apresenta-se mais intenso, pois a instituição escolar é um ambiente

\footnotetext{
${ }^{3} \mathrm{O}$ termo é amplamente teorizado pelo autor no texto "A criança e a cultura lúdica", publicado na obra "O brincar e suas teorias", de Kishimoto (2017).
} 
social que recebe todas as pessoas, independentemente de suas diferenças e contextos socioculturais. A conduta lúdica, como afirma Kishimotto (2017, p. 140-143), "oferece oportunidades para experimentar comportamentos que, em situações normais, jamais seriam tentados pelo medo do erro e punição. (...) ao minimizar as consequências da ação, contribui para a exploração e flexibilidade do ser que brinca."

Nessa perspectiva, por meio das atividades lúdicas, o lúdico pode contribuir como linguagem plural, na medida em que se adequa a cada um, e assim possibilita ao professor, na condição de mediador, fomentar suas aulas, tornando as atividades lugar de emergência e desenvolvimento de uma cultura lúdica. A cultura lúdica na escola tem um importante papel educativo, sobretudo nas aulas de matemática, desde que reconhecida pelos envolvidos no processo educativo dos alunos. Portanto, é notável a importância de uma prática educativa lúdica que considere a relação entre cultura, ludicidade e formação humana. É importante ressaltar que o ser humano carrega consigo a habilidade de desenvolver disposições lúdicas na realização de suas ações. Essa habilidade prepara-o para aprender, em primeira fase, condições básicas de existência. De forma lúdica, vivencia a corporeidade e aperfeiçoa amplamente os fatores psicomotores, nota seu corpo e os usos que este pode lhe proporcionar. No campo educativo, o lúdico fornece subsídios que o caracterizam como preparação espontânea para o real.

No entanto, apesar de as atividades direcionadas aos alunos serem preenchidas de objetivos e intenções, é notório que eles podem vivenciá-las também de outras formas, em momentos e ambientes além da sala de aula, como no intervalo (recreio), que oferece, em determinadas instituições escolares, momentos livres capazes de lhes proporcionar possibilidades de desenvolvimento pleno. Segundo Dantas (2017, p. 115), “(...) dizer que a atividade infantil é lúdica, isto é, gratuita, não significa que ela não atenda às necessidades do desenvolvimento. Para promover a disseminação de uma prática educativa que seja norteada por atividades lúdicas, o professor precisa reconhecer que o ambiente escolar é composto por atividades lúdicas e também de atividades não-lúdicas, assim as possibilidades de aprendizagens dos alunos serão potencializadas, desde que o equilíbrio entre essas atividades seja respeitado e bem fundamentado.

\subsection{Prática Pedagógica e Prática Pedagógica Lúdica: Síntese de conceitos}

Teorizar sobre PP e PPL implica em ter clareza sobre a imbricação das suas terminologias e definições conceituais no contexto da educação. A PPL não se sobrepõe à PP, 
mas utiliza-se dela para atingir o seu objetivo - desenvolvimento consciente de ações de ensino significativas, prazerosas e sensíveis para todos os envolvidos no processo de ensinar e aprender.

Todavia, o significado que a PP assume na escola, partindo de uma visão crítica, varia de acordo com os princípios, conhecimentos e concepções dos sujeitos envolvidos no processo educativo. Ela se constitui como uma ação dialógica que envolve, de forma crítica, todos os sujeitos da escola. Libâneo (2001), ao teorizar sobre a PP, entendida como ação educativa intencional e crítica do professor, afirma que ela não deve ocorrer de forma isolada das relações sociais que caracterizam a estrutura econômica e política de uma sociedade. Nota-se nas asseverações do autor que ela é dialógica e que sua compreensão e desenvolvimento exigem pensamento crítico e deliberado dos sujeitos envolvidos no processo educativo. A respeito de seu conceito, Fernandes (2008, p. 158-159) entende a PP como

(...) prática intencional de ensino e aprendizagem não reduzida à questão didática ou às metodologias de estudar e de aprender, mas articulada à educação como prática social e ao conhecimento como produção histórica e social, datada e situada, numa relação dialética entre prática-teoria, conteúdo-forma e perspectivas interdisciplinares.

Corroborando essa definição, Franco (2016) afirma que uma aula se move pelo viés da PP quando está organizada pelos professores em torno do seguinte: intencionalidades, práticas que dão sentido às intencionalidades e reflexão crítica e contínua para avaliar se as intencionalidades estão atingindo todos os envolvidos no processo de ensino. Nesta linha de raciocínio, a autora ressalta que as relações humanas constituintes do cotidiano escolar, os exemplos e testemunhos apreendidos pelos estudantes, os rituais e as práticas sociais que acontecem no ambiente escolar e acadêmico se incluem nos conhecimentos escolarizados e, na maioria das vezes, são esses os que marcam a formação dos estudantes, mais do que as aprendizagens das diferentes matérias de ensino.

Sob esta vertente teórica, pode-se afirmar que, além de o professor dispor de conhecimentos específicos para atuar na sua área de ensino, é preciso que ele desenvolva uma PP que conduza seus alunos à participação crítica na sociedade, transformando-a e, concomitantemente, sendo transformados. Franco (2016) aponta, ainda, que a PP envolve as circunstâncias da formação, os espaços-tempos escolares, as opções da organização do trabalho docente, as parcerias e as expectativas do docente. Ou seja, na PP devem estar presentes não só as técnicas didáticas utilizadas, mas, também, as perspectivas e expectativas profissionais, além dos processos de formação e dos impactos sociais e culturais do espaço ensinante, dentre outros 
aspectos que conferem uma enorme complexidade a este momento da docência. Sendo assim, a autora enfatiza que nas práticas pedagogicamente construídas há a mediação do humano e não a submissão do humano a um artefato técnico previamente construído. Desta maneira, uma aula ou um encontro educativo tornar-se-á uma PP quando se organizar em torno de intencionalidades, incorporar a reflexão contínua e coletiva, para assegurar que a intencionalidade proposta seja compreendida por todos.

A autora supracitada assevera que, para o professor exercer algum papel de agente de transformação social, é importante que ele tenha conhecimento de toda essa complexidade de fatores que influenciam sua prática pedagógica, e aqui inclui-se também a PPL. Esse conjunto de conhecimentos, constitui a teoria da prática e pode ser compreendido como a antecipação ideal de uma expectativa real. Neste sentido, as ações desse professor serão direcionadas por uma intencionalidade, consciente, planejada e refletida, e o cotidiano prático de suas aulas será rompido para pausas de reflexão crítica que determinarão seu fazer pedagógico. Nessas circunstâncias, o professor nega a realidade imposta e concretiza seu trabalho por meio da práxis pedagógica. Observa-se que essas proposições teóricas indicam que a maneira de conduzir o ensino e selecionar os interesses para a aprendizagem dos alunos encontra-se associada às percepções dos professores acerca das relações com o mundo. Caldeira e Zaidan (2010, p. 21), ao definirem PP, afirmam que ela é

(...) entendida como uma prática social complexa, acontece em diferentes espaços/tempos da escola, no cotidiano de professores e alunos nela envolvidos e, de modo especial, na sala de aula, mediada pela interação professor-aluno-conhecimento. Nela estão imbricados, simultaneamente, elementos particulares e gerais.

Afirmam, ainda, que particularidades do professor no contexto geral da PP são marcadas por "sua experiência, sua corporeidade, sua formação, condições de trabalho e escolhas profissionais". Na visão de Gadotti (2013), a PP, como processo social, admite princípios de totalidade, movimento, mudança qualitativa e contradição. Ela é dialética e orientada por elementos externos à escola. Deste modo, este estudo considera que as concepções da PP de professores influenciam de maneira positiva ou negativa a ação educativa e determinam o modo de conduzir o ensino e de conceber sua aprendizagem. A esse respeito, afirma-se nesta pesquisa que a PP deve conduzir a uma educação transformadora, crítica, centrada na condição humana, no desenvolvimento da compreensão, da sensibilidade e da ética, na diversidade cultural, na diversidade de indivíduos e que privilegie a construção de um conhecimento significativo para a vida e transdisciplinar. Nesta direção, Sacristán e Gómez (2009) alertam que: 
(...) sem compreender o que se faz, a prática pedagógica é mera reprodução de hábitos existentes, ou respostas que os docentes devem fornecer a demandas e ordens externas, e que (...) para transformar, é preciso ter consciência e compreensão das dimensões que se entrecruzam na prática dentro da qual nos movemos.

Mediante essas considerações, subtende-se que a atividade docente é permeada por uma pluralidade de saberes norteados pelos aspectos profissionais e políticos que influenciam a ação do professor em sala de aula. Assim, compreende-se que a intencionalidade na PP se remete à forma de organização anterior ao momento aula, ou seja, consciente, planejada e efetiva, a fim de conduzir um ensino que não se restringe apenas aos conteúdos, mas, para além do ambiente escolar. Neste sentido, para se configurar como PP, implica o desenvolvimento de um planejamento intencional que conduza a procedimentos metodológicos elaborados em conformidade com o outro, baseados nas suas diferenças linguísticas, cognitivas, físicas, sociais e culturais, que vise à transformação social. Logo, este trabalho orienta-se pelo conceito de PP como prática social, intencional e crítica e parte do princípio de uma educação transformadora, sendo um compromisso ético e político. As proposições teóricas apresentadas evidenciam que a PP transcorre por um processo de conscientização dos professores, em momento anterior à aula. Este fato fortalece o entendimento de que, no ambiente escolar, o professor não desenvolve apenas um exercício técnico. Sua função implica, dentre outras coisas, a divulgação da cultura na perspectiva de ser aquele que detém um poder simbólico e institucional para condução das formas culturais de pensar e agir em sociedade.

A PPL assume todas as definições teóricas e as intencionalidades da PP, porque emerge de uma prática pedagógica, no entanto, envolve, ainda, ações pedagógicas significativas, prazerosas e sensíveis que têm como objetivo final envolver, os sujeitos aprendizes no processo de ensinar e aprender, com prazer.

\section{METODOLOGIA}

Como investigar a PP e PPL com base na perspectiva das professoras dos anos iniciais do Ensino Fundamental? O ponto de partida para a produção de dados que respondessem à pergunta anterior exigiu dos pesquisadores uma imersão aprofundada no contexto da escola investigada. Primeiramente, foi preciso conhecer a história de sua criação, sua localidade, estrutura física, a comunidade escolar, os profissionais da educação que ali atuam, projetos e planos de trabalho dos professores, para, depois, inserir-se no universo da investigação sobre as práticas desenvolvidas pelos docentes. 
A pesquisa caracteriza-se como um estudo de caso de natureza qualitativa. O local selecionado para a pesquisa foi uma escola de Educação Básica de Salvador-BA. O critério que determinou a escolha da unidade foi a comprovação feita ao pesquisador, no momento de sondagem dos locais para desenvolvimento da pesquisa, de que a unidade ofertava os primeiros ciclos de escolaridade básica, seguida da aprovação da pesquisa na escola pela Secretaria Municipal de Educação (SME) da cidade de Salvador e aceitação da pesquisa, in lócus, pela equipe pedagógica e professores que ministravam a disciplina de matemática no primeiro e segundo ciclos de escolarização.

Os colaboradores selecionados para a produção de dados na pesquisa foram as professoras em exercício docente na área de matemática nos dois primeiros ciclos dos anos iniciais do Ensino Fundamental. O critério para escolha dos participantes foi atuar nos anos iniciais com a disciplina de matemática e possuir formação inicial em pedagogia ou matemática. O período que a pesquisa empírica levou para ser desenvolvida foi de agosto 2018 a fevereiro de 2019, contando com um número de 04 (quatro) professoras, as quais serão chamadas pelos codinomes P1, P2, P3 e P4. A atividade de pesquisa ocorreu em 6 momentos: $1^{\circ}$ conhecimento da rede municipal de ensino; $2^{\circ}$ escolha da unidade escolar; $3^{\circ}$ solicitação de autorização para a realização da pesquisa; $4^{\circ}$ conhecimento da unidade escolar; $5^{\circ}$ entrevistas; $6^{\circ}$ realização da observação.

As fontes de pesquisa da investigação foram: entrevista semiestruturada, documentos escolares, e observação das aulas. A elaboração dos instrumentos adotados na pesquisa baseouse nas ideias apresentadas no referencial teórico e nas suas implicações em termos de estudo das práticas. Ressalta-se que a utilização das técnicas e a periodização de tais momentos foram necessárias e fundamentais para um maior entendimento e sistematização da coleta de dados e da pesquisa. As técnicas de investigação foram adotadas tendo em vista o enfoque interpretativo presente na abordagem do tema e a natureza do objeto de estudo, a PPL. O método para análise das falas e da prática das professoras foi o interpretativo, baseado na Análise de Conteúdo teorizada por Bardin. A organização do material de análise foi sistematizada em quatro momentos distintos: organização do material produzido; transcrição e organização das entrevistas; seleção de trechos do caderno de pesquisa em que o pesquisador descreveu o desenvolvimento da PPL das professoras.

\section{ANÁLISES E RESULTADOS}

A presença de uma multiplicidade de respostas, tanto nas entrevistas, quanto nos 
documentos e anotações no caderno de pesquisa, focos de análise do texto apresentado, direcionou a utilização de eixos de análise. Assim, tendo como orientação para a análise o quadro teórico, o objeto estudado e as informações obtidas, procedeu-se ao agrupamento dos dados para análise, dispondo-se esta, a priori, em três eixos: 1) Ensino da matemática; 2) Prática Pedagógica; 3) Prática Pedagógica Lúdica.

\subsection{Ensino da matemática na sala de aula}

Analisar a prática do outro, neste caso, do professor de matemática, não é uma atividade de pesquisa fácil. Ao pesquisador, é necessário criar estratégias de coleta de informação que permitam ao "outro", o colaborador, desenvolver seu trabalho sem muitas interferências. As "interferências do pesquisador" podem conduzir a mudanças de hábito, de trabalho e de relação com os alunos. Por este motivo, visando uma maior aproximação dos colaboradores da pesquisa, o pesquisador direcionou a sua participação, também, para as atividades de acompanhamento do trabalho do professor na sala. O Quadro 1, a seguir, apresenta excertos das falas dos professores no tocante ao "ensino da matemática".

\begin{tabular}{l} 
Excertos das falas dos professores \\
\hline P1: “Sempre que eu tô dando aula faço a relação [...] Se não souber ler não vai entender a matemática." \\
\hline P2: “Matemática pra mim é o raciocínio. Como se dá o raciocínio de cada criança. Como estudar as \\
estratégias de cada criança.” "ensino de forma articulada”. \\
\hline P3: “...exige muita abstração do aluno”. \\
\hline $\begin{array}{l}\text { P4: “... é pensar no ensino que conduz a criança a aprender sobre números, grandezas e medidas. Mas não é } \\
\text { uma aprendizagem mecânica”. }\end{array}$
\end{tabular}

Quadro 1 - Ensino da matemática na sala de aula

Fonte: Entrevista e caderno de registro do pesquisador. 2018/2019

As informações do quadro anterior revelam as concepções dos professores sobre o ensino da matemática, que podem ser agrupadas em dois blocos. No bloco 1: "relação" (P1) e "articulação e abstração" (P3), P1 e P3 concebem a matemática como uma construção humana, opondo-se à ideia simplista e reducionista de que ela é um conteúdo a ser ensinado pela escola e aprendido pelo aluno; significa que há, em suas práticas pedagógicas, a compreensão de que a aquisição do conhecimento matemático pela criança é mediada por relações sociais e culturais e se consolidam num processo complexo. Assim, a escola não assume a primazia sobre a função de ensinar o conteúdo matemático, mas sim de ajudar o aluno a construir o seu próprio conhecimento.

No bloco 2, há as seguintes opiniões sobre a matemática: é "raciocínio" (P2) e "aprender números, medidas e grandezas" (P4). Portanto, descrevem a matemática como uma ciência pura 
e acabada; assim, para aprendê-la, exige-se abstração pura e raciocínio lógico apurado. Nessa perspectiva, a prática do professor baseia-se na aplicação de exercícios padronizados para os alunos pensarem e responderem. Com base nas palavras das professoras, pode-se afirmar, ainda, a validação das concepções embasadas na primazia do formalismo matemático - o professor como intermediário entre o aluno e o objeto de estudo, o ensinar transmitindo conhecimentos , nessa vertente, o aprendiz não tem contato com o objeto estudado, mas com o discurso livresco ou, ainda, com e pela exposição verbal do professor.

A seguir, com base nas informações produzidas nos projetos pedagógicos, planejamento e observação, apresentam-se, no Quadro 2, os conteúdos trabalhados em sala e análise interpretativa da PP desenvolvida por P1, P2, P3 e P4, na sala de aula.

\begin{tabular}{|c|l|l|}
\hline Professor & \multicolumn{1}{|c|}{ Conteúdo } & \multicolumn{1}{c|}{ PP } \\
\hline P1 & $\begin{array}{l}\text { Tratamento da } \\
\text { informação }\end{array}$ & $\begin{array}{l}\text { Método expositivo; Uso do livro didático; Problematização; Conhecimento } \\
\text { matemático frágil. }\end{array}$ \\
\hline P2 & Divisão & $\begin{array}{l}\text { Método expositivo; Uso do livro didático; Énfase na realização de } \\
\text { exercícios; Conhecimento matemático frágil. }\end{array}$ \\
\hline P3 & $\begin{array}{l}\text { Fração } \\
\text { equivalente }\end{array}$ & $\begin{array}{l}\text { Método expositivo; Livro didático como orientador da ação pedagógica; } \\
\text { Conhecimentos matemático frágil. }\end{array}$ \\
\hline P4 & Multiplicação & $\begin{array}{l}\text { Método expositivo; Livro didático como orientador da ação pedagógica; } \\
\text { Conhecimento matemático frágil. }\end{array}$ \\
\hline
\end{tabular}

Quadro 2 - Prática Pedagógica desenvolvida nas aulas de matemática

Fonte: Entrevista e caderno de registro do pesquisador. 2019

Ao estabelecer um comparativo entre os discursos sobre a matemática e os apontamentos do caderno de pesquisa, observa-se que a PP realizada nem sempre segue a mesma linha do discurso. As falas dos professores P1 e P3 apontam uma concepção de que a matemática é uma ciência das relações e construção humana. Tal visão, por considerar a cultura, entendendo que as práticas lúdicas estão presentes na cultura, possibilita o desenvolvimento da PPL. No entanto, a observação das aulas de P1 e P3 demonstram que suas práticas são efetivadas com base na resolução de atividades dos livros. O ponto positivo é que elas apresentam um esforço considerável para desenvolver um ensino de forma significativa e que, neste processo, o aluno tenha prazer em resolver a atividade matemática. Ao permitirem que as crianças se utilizem de jogos e realizem atividades em grupo, as professoras imprimem intencionalidade lúdica à aula, com isso, tornam o processo de aprender e ensinar lúdico. As informações produzidas no momento da observação permitiram constatar que os alunos, com esta ação intencional, sentem-se envolvidos nas atividades, trocam ideias, discutem formas diferentes de resolução das atividades e vibram quando acertam as questões/atividades propostas pela professora. Apreender passa a ser entendido pelos alunos como uma ação 
desafiante e prazerosa que exige deles conhecimentos acerca do conteúdo matemático.

As professoras P2 e P4, por sua vez, desenvolvem a ação docente seguindo um modelo pré-estabelecido para a resolução de atividades matemáticas. A prática de P2 e P4 orienta-se em atividades de resolução e correção de exercícios dos livros didáticos. Neste contexto, tem pouca relevância a relação entre a linguagem materna e a linguagem matemática e outros artefatos e alternativas didático-metodológicas para ensinar matemática. As concepções de P2 e P4 reafirmam os dados de pesquisas na área de educação matemática, ou seja, de que a maioria dos professores ainda considera a matemática como ciência de exatidão. Esta compreensão não admite espaço para o desenvolvimento de uma PPL pelo professor. O importante é aplicar o modelo de ensino pré-estabelecido no livro didático.

Silva (2017), ao teorizar sobre o ensino da matemática na escola, defende a ideia de que, quando se pretende uma aprendizagem significativa, o ensino deve ir além de simples técnicas de reprodução de modelos padronizados que visem apenas à aplicação futura do conhecimento matemático na sala de aula. A ação de ensinar deve implicar, de forma intencional, um diálogo entre os conhecimentos prévios e os novos, bem como a valorização dos conceitos científicos e habilidades dos alunos. A aprendizagem da matemática, partindo de uma PPL, deve ser, em boa parte, um processo de abstração progressiva que conduza o aluno, ao longo do processo escolar, à compreensão de ideias e construção de conceitos matemáticos. No entanto, quanto às discussões sobre as PPL dos professores que ensinam matemática, é necessário que se compreenda que as experiências matemáticas pessoais, escolares e culturais dos sujeitos de aprendizagem podem servir de ferramenta para tais comprovações. As experiências negativas com a matemática e sua aprendizagem comprometem, fortemente, a vida e o desenvolvimento da PP dos docentes.

A visão do ensino dessa disciplina nos anos iniciais do Ensino Fundamental deve sobrepujar as práticas baseadas em métodos e técnicas pré-estabelecidas, a aplicação de exercícios padronizados, e assumir como função elementar o desenvolvimento e o estímulo da criatividade, bem como a investigação científica, demonstrando que a matemática, ao contrário do que afirmam as concepções e tendências tradicionais, é uma ciência que está sendo construída pelo homem constantemente, sempre necessitando de modificações e adaptações, razão pela qual é crucial entender a matemática na condição de construção humana. Exige-se um repensar crítico acerca da prática, do valor formativo dos conteúdos a serem ensinados, das metodologias escolhidas e dos modos de ensinar a aprender e uma clareza das tendências atuais presentes nas propostas curriculares; enfim, os docentes necessitam saber o que, para que e como ensinar matemática na escola. 


\subsection{Prática Pedagógica}

Assume-se, com base no referencial teórico, que a PP e a PPL devem ser desenvolvidas de forma intencional, consciente, objetivando transformação na sala de aula. Entendidas assim, admite-se, também, que o desenvolvimento da ação educativa exige de quem ensina pensamento reflexivo crítico, compreensão concisa da educação, das ciências da educação e, sobretudo, dos processos de ensinar e aprender na escola. O professor deve possuir conhecimentos e saberes sobre a docência, conhecimento específico do conteúdo e da área que se propõe ensinar. Neste caso, o conhecimento da matemática.

No entanto, autores que investigam as práticas no contexto educacional são categóricos ao afirmarem que o exercício contínuo da PP e PPL exige reflexão crítica de todos os envolvidos no processo de ensinar na escola. Desta forma, a efetivação da PP do professor, sobretudo da PPL, não resulta, apenas, de um movimento solitário emergido das suas experiências formativas e práticas, mas, também, do diálogo realizado entre todos os envolvidos no processo educativo. Prática intencional e crítica exige diálogo, enfrentamento, sensibilidade e reflexão crítica sobre a ação docente na escola. Não se resume com a terminalidade do planejamento de atividades educativas bem-sucedidas, mas no movimento contínuo e crítico da ação docente, intencional e crítica. Exige ação, reflexão e ação crítica sobre o processo de ensinar e aprender na escola.

A seguir, apresenta-se o Quadro 3, contendo excertos da fala das professoras P1, P2, P3 e P4 sobre a PP e análise interpretativa das ações didáticas desenvolvidas por elas em sala de aula, na disciplina de matemática.

Excertos das falas dos professores sobre a PP

P1: "ação consciente do professor".

P2: "ação consciente do meu trabalho na sala de aula”. Precisa de planejamento e sempre há uma intenção de ensinar para que o aluno aprenda".

P3: “... É uma experiência que conduz a prática transformadora [...] não é um complemento da teoria. Ela é intencional por que tem relação com a organização da aula. É uma prática direcionada, guiada pelo currículo, planejamento escolar [...]”."

P4: “... tem que ter uma intenção”. É eu saber o que é que eu quero daquilo que eu quero ensinar. ... O objetivo para a vida do aluno”.

Quadro3 - Prática Pedagógica dos professores

Fonte: Entrevista e caderno de registro do pesquisador. 2019

A análise interpretativa dos excertos de falas das professoras P1, P2, P3 e P4, sobre o eixo "Pratica pedagógica", revela que possuem compreensão de que a PP é uma ação educativa intencional e consciente. Na fala das professoras, PP significa: "ação consciente do professor" (P1), "ação consciente do meu trabalho" (P2), "experiencia que conduz a práxis" (P3) e "ela 
tem muita intenção" (P4). Acrescenta-se, conforme pode-se constatar nas falas de P2 e P3, a afirmação de que ela deve ser planejada. Sobre o seu entendimento, afirmam que a PP é um "complemento da teoria", "essencial para o trabalho docente", sua realização deve "almejar a transformação educativa" e que é uma "pratica educativa, guiada pelo currículo". Quando afirmam que a PP precisa ser planejada, pressupõem intencionalidade educativa inerente a ela; os professores impõem seriedade e consciência crítica ao ensino da matemática e à prática desenvolvida. Assevera-se que este é o primeiro passo para se realizar a PP. Assim, "planejar a ação" no sentido crítico imprime caráter de seriedade e compreensão do ato educativo contínuo, o que configura a PP.

A análise aprofundada das informações coletadas na observação participativa apontou que os professores P1, P2, P3 e P4, de certa maneira, possuem compreensão sobre o que vem a ser uma PP, pois atribuem a ela intencionalidade educativa. A prática em sala, a ação de ensinar matemática, move-se pelos caminhos da ação consciente e deliberada, o que a configura como uma PP. Observou-se que o desenvolvimento da ação dos professores é direcionado para atingir objetivos educacionais implícitos nas propostas curriculares. Todas as atividades desenvolvidas por elas, mesmos seguindo o estabelecido no livro didático e nos cadernos de exercícios, estavam articuladas com o Projeto Pedagógico, Planejamento Escolar e com as propostas pedagógicas da escola. Apesar de evidenciarem consciência sobre a ação educativa na sala de aula, ainda, desenvolvem aulas tendo como referência principal as atividades do livro didático e os cadernos de exercícios cedidos pela Secretaria Municipal de Educação (SME). Esta prática implica o engessamento da ação, reduz, em parte, a ação educativa, que no planejamento orienta-se pelo viés da PP transformadora, a uma prática de transmissão de conhecimentos. Este fato foi observado no desenvolvimento da prática de P1 e P3, visto que trabalharam os conteúdos matemáticos utilizando, exclusivamente, as atividades do livro didático e cadernos de atividades cedidos pela SME.

A ação didática pautou-se no esforço considerável para conduzir as crianças à realização das atividades propostas, 'retiradas' do livro didático. Nesse sentindo, o livro é visto como "orientador" da ação pedagógica. Todavia, o ponto positivo da prática desenvolvida pelas professoras é seu esforço considerável na ação didática para tornar as aulas momentos lúdicos aos alunos. O desejo de desenvolver uma PPL conduziu as docentes a recorrerem a atividades lúdicas envolvendo jogos, brincadeiras, dramatização de acontecimentos, alteração/mudança de voz para explicar uma atividade e autorização para os alunos utilizarem ferramentas diversas (calculadoras, celular e material concreto) na resolução das atividades propostas. 
No aprendizado da matemática, não se pode afirmar que o ato de resolver atividades do livro didático no caderno de exercícios não seja lúdico para alguns alunos, no entanto, é preciso cautela quando se discute o ensino de matemática para crianças pequenas, que gostam de aprender brincando. Nesta etapa o ensino da matemática na sala de aula é, essencialmente, baseado na resolução de exercícios padronizados do livro didático, raramente conduz os alunos à realização das atividades de forma prazerosa, pois, neste processo, o que determina a aula é o fazer a atividade. Reproduzir o estabelecido. Desse modo, toda a ação didática é norteada para a resolução das atividades e resposta corretas, impõe-se o modelo dado, devem ser seguidos os padrões de resolução. Nega-se a criatividade dos alunos, as ajudas mútuas, as discussões sobre os resultados, o prazer de vibrar ao "errar" ou "acertar" uma atividade. Para o êxito da ação, é necessário que o professor imprima disciplina ao ato de aprendizagem. Essa prática é coerente com a PPL, pois imprimir ao ato educativo a intencionalidade educativa não reduz as atividades escolares ao simplismo e muito menos ao praticismo pedagógico, pelo contrário, conduz as crianças ao 'aprender com prazer'.

Os dados construídos permitiram verificar o que as professoras depreendem sobre o conceito de PP e que procuram desenvolver aulas nesta perspectiva. No entanto, em alguns momentos do desenvolvimento da ação didática, utilizam-se da racionalidade técnica para ensinar. Este movimento da ação docente, oscilante, afiança que a prática das professoras se mova sob perspectivas e abordagens diferentes. Este fato acorre porque a ação docente é movida por um movimento de construção e reconstrução de concepções e crenças sobre a matemática e seu ensino.

\subsection{Prática Pedagógica Lúdica nas aulas de Matemática}

Inicia-se a análise interpretativa sobre a PPL, conforme o Quadro 4, a seguir, reforçando a afirmação teórica de Luckesi (2018, p. 140) sobre o lúdico: “(...) é um estado interno do sujeito que vivencia uma situação (...)”. No entanto, uma questão instigadora surge aqui e conduz à reflexão sobre PPL. Qual a diferença entre PP e PPL? A diferença está no acréscimo de que a segunda, para além das intencionalidades educativas expressas na PP, envolve, também, as ações pedagógicas significativas, prazerosas e sensíveis realizadas pelo professor e que têm como objetivo final envolver, de forma prazerosa, os sujeitos no processo de ensinar e aprender. Objetiva o alcance da satisfação pessoal dos sujeitos envolvidos para a aprendizagem do conteúdo escolar. 
As informações do quadro abaixo, apresenta as falas das professoras sobre a PPL desenvolvidas nas aulas de matemática.

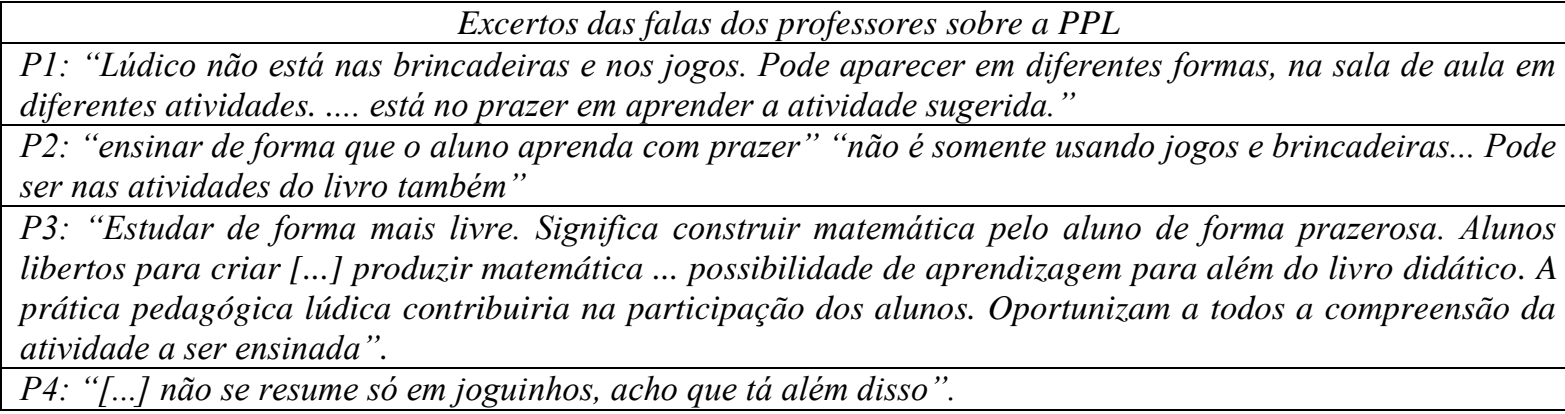

Ao serem indagadas sobre o desenvolvimento da PPL, ou seja, como trabalham nas aulas de matemática, todas as professoras apresentam pensamento muito parecido, isto é, admitem que se esforçam para desenvolver uma prática pedagógica fundamentada em discussões coletivas sobre a natureza da disciplina, preocupam-se com a forma de abordagem dos conteúdos e com o uso de metodologias diferenciadas, recursos didáticos incluindo atividades lúdicas e valorizam a articulação entre os conhecimentos prévios dos alunos e os novos conhecimentos.

Os excertos das falas das professoras investigadas sobre a PPL revelam que elas possuem uma visão crítica sobre o conceito. No tocante a PPL, asseveram:

P1 “[...] lúdico não está nas brincadeiras e nos jogos. Pode aparecer em diferentes formas, na sala de aula em diferentes atividades. Lúdico está no prazer em aprender a atividade sugerida".

P2 "Ensinar de forma que o aluno aprenda com prazer" "[...] pode ser no livro".

$P 3$ "[...] estudar de forma mais livre".

P4 “[...] não se resume só em joguinhos”.

Dos excertos destacados pode-se afirmar que as professoras não conceituam teoricamente PPL - ensino lúdico -, no entanto, utilizam-se da palavra "lúdico" para explicar a definição e seu desenvolvimento em sala de aula. Foram categóricas ao afirmar que o desenvolvimento da PPL não acontece somente com a utilização de jogos e brincadeiras. Enriquecem a discussão quando apontam que PPL implica o desenvolvimento de uma ação pedagógica consciente que conduza o aprender com prazer, entrega plena à atividade.

Corroborando a fala das professoras sobre o ensino lúdico, Maheu (2007, p. 27) afirma que

[...] o ensino lúdico significa ensinar um dado objeto de conhecimento na dança da 
dialética entre focalização e ampliação do olhar. [...] o ensino lúdico é aquele em que se inserem conteúdos, métodos criativos e o elevo em se ensinar e, principalmente, aprender.

A citação reforça a defesa sobre a intencionalidade educativa assumida na pesquisa. Prática pedagógica lúdica se materializa mediante intencionalidade e desenvolvimento crítico da ação pedagógica. A fala dos professores coaduna com o que fazem em sala de aula, ou seja, a prática pedagógica. Observou-se na entrevista que P1, P2, P3 e P4 esforçam-se para desenvolver nas aulas de matemática uma prática de ensino que envolva os alunos no processo de apreender com prazer, fundada nos modos de fazer e agir dos alunos, incentivo para a aprendizagem, e, quando possível, porque não é uma prática habitual, envolvem jogos e brincadeiras na realização da atividade.

P1, P2, P3 e P4 afirmam que as atividades lúdicas desenvolvidas nas aulas de matemática não devem ser utilizadas, apenas, como acessório para a execução da PPL em sala de aula. Apresentam clareza de que os jogos e as brincadeiras sem intencionalidade educativa perdem o sentido pedagógico, tornando-se meras atividades utilitário-pedagógicas. Opõem-se, ainda, à ideia simplista de que os mesmos, por serem “atividades lúdicas”, resolvem o problema da não aprendizagem em matemática.

As informações obtidas na observação durante a pesquisa sobre as aulas das professoras permitem-nos afirmar que as ações educativas desenvolvidas por elas foram direcionadas na busca do alcance da PPL, com objetivo de conduzir os alunos a aprender com prazer. A observação permitiu também afirmar que a PPL não se concretiza na atividade em si, mas na ação subjetiva, sensível e consciente desenvolvida pelo professor. No desejo de desenvolver-se em um movimento de prazer pleno entre todos os envolvidos no processo de ensinar e aprender.

As professoras P1, P2, P3 e P4, de certa maneira, possuem compreensão sobre o que significa uma prática pedagógica, pois atribuem a ela intencionalidade educativa. Observou-se que o desenvolvimento da ação das professoras é direcionado para atingir objetivos educacionais implícitos nas propostas curriculares. Todas as atividades desenvolvidas por elas, mesmos seguindo o estabelecido no livro didático e nos cadernos de exercícios do município, estavam articuladas com o projeto pedagógico, planejamento escolar e com as propostas estabelecidas nos projetos pedagógicos da escola.

No entanto, em razão do desejo de desenvolver uma prática pedagógica lúdica, são conduzidas à realização de atividades lúdicas, por meio de jogos, brincadeiras, dramatização de acontecimentos, alteração e mudança de voz para explicar uma atividade e autorização para os alunos utilizarem ferramentas diversas (calculadoras, celular e material concreto), a fim de 
resolverem as atividades propostas.

A ação das professoras, no que se refere ao desenvolvimento da aula, norteia-se no viés da PPL, mesmo tendo como referência às atividades impostas pelo livro didático. Ao permitir que as crianças façam uso de jogos, brincadeiras e realização de atividades em grupo, as professoras imprimem intencionalidade lúdica à aula; com isso, tornam o processo de aprender e ensinar mais próximo àquilo que se entende por PPL.

\section{CONSIDERAÇÕES}

As professoras revelaram possuir compreensão e visão crítica sobre o conceito da PPL, uma vez que foram categóricas ao afirmar que o desenvolvimento da ludicidade não acontece somente com a utilização de jogos e brincadeiras na sala de aula. Desse modo, enriqueceram a discussão ao apontarem que o desenvolvimento da PPL implica uma ação pedagógica deliberada que conduza o aluno a aprender com prazer, entrega de forma plena à atividade. No entanto, ficou evidente nos momentos de observação das aulas que a prática pedagógica cotidiana das mesmas oscila entre atividades impostas sem caráter lúdico e atividades lúdicas. Esta constatação demostra que a prática dos professores é conduzida por um movimento não linear e orienta-se por crenças, concepções e tendências diferentes sobre a educação, propostas pedagógicas e ensino da matemática.

Destaca-se, ainda, que as professoras se opõem à ideia simplista de que os jogos e as brincadeiras, por serem entendidas como "atividades lúdicas", resolvem o problema da não aprendizagem em matemática. A observação da prática revelou a compreensão das professoras de que é necessária uma reflexão crítica sobre as alternativas didáticas escolhidas para ensinar, sobretudo quando se pretende desenvolver a PPL. De acordo com elas, de forma categórica, o desenvolvimento da ludicidade não acontece somente com a utilização de jogos e brincadeiras, pois o estado de ludicidade pode ser atingido, também, com atividades ditas "não lúdicas" pela escola. Toda a ação educativa na sala de aula, segundo as professoras P1, P2, P3 e P4, deve partir de uma intencionalidade educativa que desperte na criança o prazer em aprender os conteúdos escolares.

As informações produzidas na pesquisa comprovam, também, que a prática pedagógica lúdica, por ser intencional, e distanciar-se da ideia de desenvolvimento de atividades utilitáriopedagógica, só se efetiva em um processo gerador de desequilíbrio da ação do professor, quando ele reflete sobre a importância da matemática e sua aprendizagem para os alunos. Isso acontece no quadro de vivências pessoais intensas, com a participação nos processos formativos, 
diálogos com os docentes que ensinam a mesma disciplina - com o compartilhamento de saberes/conhecimentos e experiência -, na reflexão sobre a prática e a aprendizagem dos alunos e, ainda, em um movimento que tenha a prática reflexiva crítica sobre a docência como estratégia para contribuir com essas mudanças.

\section{REFERÊNCIAS}

BEMVENUTI, A. O jogo na história: aspectos a desvelar. BEMVENUTI, A.; BEMVENUTI, A. (Org). In: O Lúdico na prática pedagógica. Curitiba: Ibpex, 2013. p. 13-32.

BRESSAN, J. C. M. Concepções e práticas de professores sobre o lúdico nas escolas organizadas por ciclos de formação humana. 2014 (Dissertação de Mestrado em Educação/UFMT/PPGedu.

BROUGÈRE, G. A Criança e a Cultura lúdica. In: KISHIMOTO, T. M. (org.) O Brincar e suas Teorias. São Paulo: Cengage Learning, 2017. p. 19-32.

CALDEIRA, A, M. S.; ZAIDAN, S. Prática pedagógica. In: OLIVEIRA, D. A.; DUARTE, A. C.; VIEIRA, L. M. F. (Org.). Dicionário: trabalho, profissão e condição docente. Belo Horizonte: GESTRADO/FaE/UFMG, 2010. v. 1.

DANTAS, H. Brincar e trabalhar. In: KISHIMOTO, T, M. (org.). O brincar e suas teorias. São Paulo: Cengage Learning, 2017. p. 111-122.

FERNANDES, C. À procura da senha da vida-de-senha a aula dialógica? In: VEIGA, I. P. A. (Org.). Aula: gênese, dimensões, princípios e práticas. Campinas: Papirus, 2008. p. 145-164.

FRANCO, M. A. R. S. Prática Pedagógica e docência: um olhar a partir da epistemologia do conceito. In: Rev. Bras. Estudos Pedagógicos. (on-line), Brasília, v. 97, n. 247, set./dez. 2016. GADOTTI, M. Pedagogia da práxis. São Paulo: Cortez, 2013.

HUIZINGA, J. Homo Ludens vom Unprung der Kulturim Spiel. SP: Perspectiva, 2000.

KISHIMOTO, T. M. O jogo e a educação infantil. In: KISHIMOTO, T. M. (org.). Jogo, brinquedo, brincadeira e a educação. São Paulo: Cortez, 2011. p. 13-44.

KISHIMOTO, T. M. Bruner e a brincadeira. In: KISHIMOTO, T. M. (org). O brincar e suas teorias. São Paulo: Cengage Learning, 2017. p. 139-154.

LIBÂNEO, J. C. Pedagogia e pedagogos. In: Educar, Curitiba, n. 17, p. 153-176, 2001.

LOPES, C. Design e ludicidade. In: EntreIdeias. Vol. 3. № 2. Salvador: UFBA, 2014.

LUCKESI, C. C. Ludicidade e atividades lúdicas: uma abordagem a partir da experiência interna, Educação e Ludicidade, Ensaios 02. Faced/UFBA, 2002.

LUCKESI, C. C. Ludicidade e formação do educador. In: EntreIdeias. Vol. 3. N 2. Salvador: UFBA/FACED, 2014. 
LUCKESI, C. C. Brincadeiras, jogos e ludicidade. In: D’ÁVILA, C.; FORTUNA, T. R. Ludicidade, cultura e formação de professores. Curitiba: CRV, 2018. p. 135-142.

MAHEU, C. D’Ávila. Eclipse do lúdico. In: Educação e Ludicidade: ensaios. № 4. Salvador: UFBA, FACED, 2007.

SILVA, A. C. da. Ensino e aprendizagem da matemática: (re)elaboração de concepções e práticas docentes. 1. ed. Niemcy: Novas Edições Acadêmicas, 2017.

WINNICOTT, D. W. O brincar e a realidade. Rio de Janeiro: Imago, 1975.

Submetido em: 15 de março de 2020.

Aprovado em: 05 de abril de 2020. 